\title{
PENAMPILAN BEBERAPA VARIETAS TOMAT PADA DUA KONDISI LINGKUNGAN
}

\author{
PERFORMANCE OF TOMATTO VARIETIES IN TWO CONDITION OF ENVIRONMENT \\ Jantje Pongoh $\left.{ }^{*}\right)$ \\ *Jurusan Budidaya Pertanian Fakultas Pertanian Unsrat Manado_95115
}

\begin{abstract}
Increasing tomato production could be approach by various ways such as intensification and extensification programs. The programs should be supported by availability of seeds and good varieties produced by breeder. Department of Agriculture has released several high yielding varieties. Tomato grows in a variety of altitude, both the highlands and lowlands, depending on variety. Therefore, ability of adaptation on specific location of tomato variety should be assessed. In relation to that, performance of six tomato varieties was evaluated on two different environments. The experiment was used factorial design. The results showed that performance some varieties varied between the two different environments. Alista variety and Victory F1 revelead good performance on characters fruit weight and fruit diameter.This two varieties could be used for breeding material. Tomatoes planted on double row space showed better performance then others. Genetic similirity pattern on different row space was resulting different response.
\end{abstract}

Keywords : Performance, variety, environment, similirity

\begin{abstract}
ABSTRAK
Untuk meningkatkan produksi tomat dapat dilakukan dengan berbagai cara seperti intensifikasi maupun ekstensifikasi. Guna menopang program tersebut perlu ditunjang dengan ketersediaan benih atau varietas unggul yang dihasilkan para pemulia. Departemen Pertanian telah melepas beberapa varietas unggul. Tanaman tomat dapat tumbuh di berbagai ketinggian tempat, baik di dataran tinggi maupun di dataran rendah, tergantung varietasnya. Juga, kecocokan suatu varietas pada kondisi tertentu yang dinamakan spesifik lokasi juga perlu diketahui. Untuk maksud tersebut ingin dipelajari bagaimana penampilan beberapa varietas tomat pada dua kondisi lingkungan jarak tanam. Berkenan dengan itu pada masing-masing kondisi lingkungan ditanam enam varietas tomat mengikuti pola percobaan faktorial. Hasil penelitian, ternyata penampilan beberapa varietas tomat pada dua kondisi lingkungan jarak tanam bervariasi satu sama lain. Varietas Alista F1 (334,9 g/tan) dan Victory F1 (316,3 $\mathrm{g} / \mathrm{tan}$ ) yang ditanam memiliki potensi berat buah dan diameter buah terbesar dan dapat digunakan sebagai materi pemuliaan. Kondisi lingkungan jarak tanam ganda memberikan respons yang lebih baik. Pola kemiripan varietas pada ke dua kondisi lingkungan jarak tanam memberikan respons yang berbeda.
\end{abstract}

Kata kunci : Penampilan, Tomat, Lingkungan, Kemiripan

Eugenia Volume 17 No. 2 Agustus 2011 


\section{PENDAHULUAN}

Produksi tomat pada tahun 2006 mencapai 629.744 ton dan pada tahun 2005 sebesar 647.020 ton. Secara nasional, rata-rata produksi mencapai 12,64 ton/ha dan khusus di Jawa 19,96 ton/ha serta luar jawa 8,37 ton/ha. Bila dibandingkan dengan produksi di Amerika Serikat dan Eropa dapat mencapai 100 ton/ha. Rendahnya produksi tomat di Indonesia kemungkinan disebabkan varietas yang ditanam tidak cocok, kultur teknis yang kurang baik atau pemberantasan hama/penyakit yang kurang efisien. Untuk meningkatkan produksi dapat dilakukan dengan berbagai cara seperti intensifikasi maupun ekstensifikasi. Guna menopang program tersebut perlu ditunjang dengan ketersediaan benih atau varietas unggul yang dihasilkan para pemulia. Berkenan dengan itu, pada tanaman tomat sudah dilepas oleh Departemen Pertanian beberapa varietas unggul, antara lain varietas Mirah, Opal, Zamrud, Intan, Mutiara, Berlian dan Ratna. Varietas-varietas tersebut memiliki berbagai sifat yang berbeda satu sama lain seperti produksi, rasa, bentuk, umur panen, ketahanan simpan dan ketoleranan terhadap penyakit tertentu. Dari sekian banyak varietas tomat yang ada, yang banyak ditanam petani adalah tomat varietas Ratna, Berlian, Precious 206, Kingkong dan Intan. Di sisi lain, tanaman tomat dapat tumbuh di berbagai ketinggian tempat, baik di dataran tinggi maupun di dataran rendah, tergantung varietasnya.

Produksi adalah salah satu sifat akhir yang penampilannya dikendalikan oleh faktor genetik dan atau lingkungan maupun gabungan ke dua faktor tersebut. Dalam arti luas, pengertian lingkungan mencakup faktor-faktor intra maupun ekstra selluler yang dapat mempengaruhi perwujudan genotipa (Brewbaker, 1964). Itu berarti, produksi sebagai sifat akhir merupakan wujud akhir atau seringkali disebut penampilan. Menurut Mangoendidjojo (2003), sifat yang ada dapat langsung dilihat seperti warna bunga, warna daun, dan bentuk biji (berkerut atau tidak), namun ada juga yang memerlukan pengamatan dan pengukuran seperti tinggi tanaman, jumlah anakan, dan produksi. Selanjutnya sifat yang memerlukan pengukuran dikenal sebagai sifat kuantitatif dan keberadaannya ditentukan oleh faktor genetik dan sangat tergantung pada faktor lingkungan. Menurut Dahlan (1992) komponen lingkungan luar sel dapat berupa: 1) tinggi tempat dari permukaan laut, 2) temperatur (maksimum-minimum), 3) fotoperiod, 4) keasaman tanah $(\mathrm{pH})$, keracunan Aluminium (Al) dan Besi $(\mathrm{Fe}), 5)$ curah hujan dan pengairan, 6) hama penyakit dan 7) keadaan yang kurang baik lainnya (kesuburan rendah). Dijelaskan bahwa varietas yang dapat mengatasi keadaan yang tidak menguntungkan akan memiliki stabilitas yang baik dan dapat digunakan dalam program pemuliaan tanaman untuk berbagai kegiatan.

Berkenan dengan itu, kecocokan suatu varietas pada kondisi tertentu yang dinamakan spesifik lokasi juga perlu diketahui. Untuk maksud tersebut ingin dipelajari bagaimana penampilan beberapa varietas tomat pada dua kondisi lingkungan jarak tanam karena para petani $\mathrm{di}$ lapang, ada yang menanam secara tunggal yaitu satu petak hanya ada satu baris tanaman ataupun ganda di mana satu petak terdapat dua baris tanaman tomat. Cara bertanam tomat menurut Adiyoga dkk. (2004) ada dua cara, yaitu : 1) sistem bedengan dengan dua baris tanaman untuk setiap bedengan dan 2) sistem guludan dengan satu baris tanaman. Cara bedengan umumnya dilakukan di daerah dataran rendah dan medium, sedangkan cara barisan tunggal biasa dilakukan di dataran tinggi. Dalam penyiapan lahan, maka pilih lahan yang gembur dan subur yang sebelumnya tidak ditanami tomat, cabai, terong, tembakau dan kentang. Buatlah bedengan selebar 120 sampai160 $\mathrm{cm}$ untuk barisan ganda, dan 40 hingga $50 \mathrm{~cm}$ untuk barisan tunggal (Prabowo, 2007; Patrawisa, 2010).

Tujuan penelitian untuk: 1) membandingkan penampilan beberapa varietas tomat pada dua kondisi lingkungan jarak tanam, dan 2) bagaimana pola kemiripan varietas pada ke dua kondisi tersebut.

Adapun manfaat penelitian dapat berguna bagi para petani dalam memilih cara bercocok tanam tomat untuk mendapatkan produksi yang maksimal. 


\section{METODE PENELITIAN}

Penelitian dikerjakan di Kelurahan Batukota Kecamatan Malalayang Kotamadya Manado. Kegiatan dimulai dari pembibitan pada bulan April 2011 dan berakhir panen pada bulan Agustus 2011.

Bahan yang dipakai antara lain enam varietas tomat, pupuk kandang, obat-obatan hama penyakit. Adapun alat yang digunakan seperti bajak, cangkul, ajir, alat pengukur berat (timbangan analitik), tali plastik, plastik, parang, gembor, alat pengukur panjang (meter), diameter batang (jangka jorong), alat tulis menulis, kalkulator dan lain-lain.

\section{Rancangan Percobaan}

Percobaan dirancang secara faktorial dalam rancangan acak lengkap dengan lima tanaman sebagai ulangan. Faktor pertama adalah enam varietas yaitu : A (Warani F1), C (G Sakina F1), E (Alista 163 F1), F (Permata F1), G (Victory F1), dan H (Sakura F1). Faktor ke dua adalah lingkungan pertanaman dengan dua tingkat yaitu : secara tunggal (L1) dan ganda (L2).

\section{Pengamatan}

Sifat-sifat yang diamati meliputi: 1) umur berbunga (dalam hst), 2) jumlah tandan bunga pada 50 hst, 3) umur panen pertama (dalam hst), 4) jumlah buah pada umur 57 hst, 5) tinggi pada saat
58 hst (dalam cm), 6) jumlah buah yang dipanen, 7) berat buah yang dipanen (g) dan 8) diameter buah yang dipanen.

\section{Prosedur Kerja}

Langkah-langkah pelaksanaan di lapang meliputi: 1) Pengolahan lahan, 2) Penanaman, 30 Pemasangan ajir, 4) Pemangkasan, 5) Pengairan, 6) Pemupukan dan 7) Panen.

\section{Analisis data}

Data dianalisis dengan analisis ragam dan dilanjutkan dengan BNT serta analisis gerombol (Cluster analysis).

\section{HASIL DAN PEMBAHASAN}

Memperhatikan interaksi antara varietas dan lingkungan $(\mathrm{V} x \mathrm{~L})$ ternyata kombinasi varietas dan kondisi lingkungan jarak tanam memiliki penampilan umur berbunga, jumlah tandan bunga $50 \mathrm{hst}$, jumlah tandan bunga $57 \mathrm{hst}$, tinggi tanaman 58 hst, umur panen (hst), jumlah buah dipanen, diameter buah dan berat buah per tanaman ternyata bervariasi. Secara statistik hanya umur berbunga dan jumlah buah yang dipanen menunjukkan ada perbedaan kombinasi varietas dan lingkungan (Tabel 1).

Tabel 1. Penampilan beberapa sifat tanaman dari enam varietas tomat pada dua kondisi jarak tanam (Table 1. Performance some character of six tomato variety in two space condition)

\begin{tabular}{|c|c|c|c|c|c|c|c|c|c|}
\hline \multirow{2}{*}{$\begin{array}{l}\text { Lingku- } \\
\text { ngan }\end{array}$} & \multirow{2}{*}{ Varietas } & \multirow{2}{*}{$\begin{array}{l}\text { Umur } \\
\text { berbunga } \\
\text { (hst) }\end{array}$} & \multicolumn{2}{|c|}{$\begin{array}{l}\text { Jumlah tandan } \\
\text { bunga }\end{array}$} & \multirow{2}{*}{$\begin{array}{c}\text { Tinggi } \\
\text { tana- } \\
\text { man } 58 \\
\text { hst }\end{array}$} & \multirow{2}{*}{$\begin{array}{l}\text { Umur } \\
\text { panen } \\
\text { (hst) }\end{array}$} & \multirow{2}{*}{$\begin{array}{l}\text { Jumlah } \\
\text { buah } \\
\text { dipanen }\end{array}$} & \multirow{2}{*}{$\begin{array}{c}\text { Diame- } \\
\text { ter } \\
\text { buah } \\
(\mathrm{cm})\end{array}$} & \multirow{2}{*}{$\begin{array}{c}\text { Berat } \\
\text { buah/ } \\
\tan (\mathrm{g})\end{array}$} \\
\hline & & & $50 \mathrm{hst}$ & $57 \mathrm{hst}$ & & & & & \\
\hline Jarak & A (Warani F1) & $43,4 f$ & 2,2 & 4,4 & 82,6 & 76,2 & $3,6 \mathrm{a}$ & 3,0 & 93,57 \\
\hline tanam & C (G-Sakina F1) & $31,6 a$ & 9,4 & 16,0 & 83,2 & 66,2 & 15,4 efg & 3,1 & 290,74 \\
\hline \multirow[t]{4}{*}{ tunggal } & $\mathrm{E}$ (F1 Alista) & $42,6 \mathrm{ef}$ & 3,6 & 9,2 & 100,2 & 76,4 & $9,8 \mathrm{bcd}$ & 3,4 & 253,89 \\
\hline & $\mathrm{F}$ (Permata F1) & $36,4 b c$ & 4,8 & 9,0 & 90,6 & 69,8 & $10,6 \mathrm{cde}$ & 3,0 & 196,06 \\
\hline & G (Victory F1) & $39,4 \mathrm{def}$ & 5,6 & 13,4 & 115,4 & 71,2 & 13,4 defg & 3,2 & 237,18 \\
\hline & H (Sakura F1) & $36,2 a b c d$ & 4,2 & 5,4 & 91,0 & 67,8 & $5,2 \mathrm{ab}$ & 3,4 & 115,35 \\
\hline Jarak & $\mathrm{A}$ (Warani F1) & 38,2 cde & 3,2 & 5,6 & 119,2 & 69,0 & $6,8 a b c$ & 3,7 & 247,00 \\
\hline tanam & C (G-Sakina F1) & $33,4 a b$ & 10,8 & 15,4 & 104,4 & 63,0 & $16,4 \mathrm{fg}$ & 2,8 & 265,32 \\
\hline \multirow[t]{4}{*}{ ganda } & E (F1 Alista) & $32,4 a b$ & 6,6 & 13,8 & 133,2 & 68,0 & $16,8 \mathrm{fg}$ & 3,7 & 415,89 \\
\hline & $\mathrm{F}$ (Permata F1) & $35,4 a b c d$ & 4,8 & 13,0 & 84,6 & 68,0 & 12,6def & 3,1 & 275,71 \\
\hline & G (Victory F1) & $34,4 a b c d$ & 7,4 & 18,8 & 139,0 & 61,6 & $18,6 \mathrm{~g}$ & 3,2 & 395,50 \\
\hline & $\mathrm{H}$ (Sakura F1) & $36,2 \mathrm{abcd}$ & 3,4 & 5,4 & 111,2 & 70,6 & $4,6 a b$ & 3,3 & 104,51 \\
\hline \multicolumn{2}{|c|}{ BNT (interaksi VxL) } & 4,6 & tn) & tn) & tn) & $\operatorname{tn)}$ & 5,3 & tn) & tn) \\
\hline
\end{tabular}

Ket : Angka yang diikuti huruf yang sama pada kolom yang sama, tidak berbeda nyata menurut BNT 5\% 
Selanjutnya jika hanya melihat faktor tunggal saja yaitu varietas, ternyata varietas $\mathrm{F} 1$ Alista $(E)$ mempunyai rata-rata berat buah terbesar (334,9 g/tanaman) tapi tidak berbeda dengan varietas Victory F1 (G), G-Sakina F1 (C) dan Permata $F 1(F)$. Penampilan sifat dari masingmasing varietas yang diuji disajikan dalam Tabel 2 .

Membandingkan berat buah per tanaman dari ke enam varietas yang ditelaah dengan deskripsi, ternyata tidak sama. Hal ini jelas berbeda karena kondisi pertumbuhan di Batukota berada dalam masa peralihan dan curah hujan tidak maksimal atau berada dalam kondisi kekeringan. Curah hujan yang sesuai untuk pertumbuhan tanaman tomat adalah $750 \mathrm{~mm}$ hingga 1.250 $\mathrm{mm} /$ tahun. Keadaan ini berhubungan erat dengan ketersediaan air tanah bagi tanaman, terutama di daerah yang tidak terdapat irigasi teknis. Di sisi lain curah hujan yang tinggi (banyak hujan) juga dapat menghambat persarian (Prabowo, 2007).

Buah tomat yang dihasilkan bisa mencapai berat hingga $0,4 \mathrm{~kg}$ per buah atau 5 sampai $8 \mathrm{~kg}$ buah per tanaman. Selain kualitas dan buahnya yang tinggi, tanaman tomat hibrida juga mampu beradaptasi dengan berbagai kondisi agroklimat, mulai daerah dataran rendah, dataran menegah, hinggga dataran tinggi. Benih tomat yang beredar di pasaran dalam kemasan lebih dari 20 varietas (Anonim, 2007). Sebagian besar varietas tersebut termasuk kelompok hibrida turunan pertama (F1), artinya benih siap tanam itu merupakan hasil persilangan dari tanaman induk yang memiliki sifatsifat unggul. Alhasil, keturunan pertamanya itu membawa sifat-sifat unggul sang induk. Paling tidak, jika dibandingkan dengan jenis lokal, umur panen varietas hibrida lebih cepat dan potensi hasilnya lebih tinggi. Namun, bukan berarti varietas tomat hibrida tidak mempunyai kelemahan. Agar keunggulan dari varietas hibrida itu muncul, cara menanamnya harus dilakukan intensif, sesuai rekomendasi produsen benihnya. Setelah varietas hibrida ditanam dan berbuah, ternyata bijinya kurang bagus bila dijadikan benih. Hal ini disebabkan sifatsifat benih keturunan kedua ini akan kembali seperti salah satu induknya. Ini berarti, untuk kembali menanam pada periode-periode berikutnya maka harus membeli benih baru (Anonim, 2007). Pada penelitian ini dicoba enam varietas dan semua varietas yang digunakan adalah turunan pertama (F1). Berkaitan dengan itu, rekomendasi penanaman sesuai dekripsi sebagai berikut: varietas Warani F1 untuk dataran tinggi, varietas G-Sakina F1 dan F1 Alista untuk dataran rendah hingga menengah serta varietas Permata F1 untuk dataran rendah. Varietas Victory F1 dapat ditanam dari dataran rendah hingga tinggi.

Pada penelitian telah diamati delapan sifat yaitu umur berbunga, jumlah tandan bunga 50 hst dan 57 hst, tinggi tanaman 58 hst, umur panen, jumlah buah dipanen, diameter buah dan berat buah berada dalam skala ukur kuantitatif. Penampilan sifat-sifat tersebut dipengaruhi oleh lingkungan, baik intra maupun ekstra seluler. Salah satu unsur lingkungan yang dominan adalah ketersediaan air. Pertumbuhan tanaman di Batukota mengalami kekurangan air dan perlu diberi air setiap hari agar dapat berproduksi. Kemampuan tomat untuk dapat menghasilkan buah sangat tergantung pada interaksi antara pertumbuhan tanaman dan kondisi lingkungan. Menurut Anonim (2007) para peneliti tomat di Italia sudah menghasilkan jenis tomat yang tahan terhadap kekeringan. Konon, untuk memproduksi $1 \mathrm{~kg}$ tomat hanya perlu air 15 liter, sementara jenis tomat yang ada sekarang rata-rata butuh 70 liter air.

Selanjutnya apabila membandingkan kondisi lingkungan jarak tanam, dalam hal ini tanam tunggal (L1) dan tanam ganda (L2) maka didapatkan pada lingkungan ganda memberikan rata-rata berat buah per tanaman, diameter buah, jumlah buah yang dipanen, tinggi tanaman $58 \mathrm{hst}$, jumlah tandan bunga 50 hst dan 57 hst terbesar tapi umur berbunga dan umur panen tercepat (Tabel 3).

Memperhatikan kondisi lingkungan (jarak tanam tunggal dan ganda) ternyata lingkungan jarak tanam ganda memberikan respons yang lebih tinggi dibandingkan dengan jarak tanam tunggal. Diduga, jarak tanam ganda memberikan respons yang lebih baik karena faktor pembatas seperti lingkungan mikro seperti temperatur tanaman, cahaya dapat diminimalisir sehingga proses fotosintesa dapat berlangsung. 
Tabel 2.Penampilan beberapa sifat tanaman dari enam varietas tomat

(Table 2. Performance some character of six tomato variety)

\begin{tabular}{|c|c|c|c|c|c|c|c|c|}
\hline \multirow[t]{2}{*}{ Varietas } & \multirow{2}{*}{$\begin{array}{c}\text { Umur } \\
\text { berbunga } \\
\text { (hst) }\end{array}$} & \multicolumn{2}{|c|}{$\begin{array}{c}\text { Jumlah tandan } \\
\text { bunga }\end{array}$} & \multirow{2}{*}{$\begin{array}{c}\text { Tinggi } \\
\text { tanaman } \\
58 \text { hst }\end{array}$} & \multirow{2}{*}{$\begin{array}{l}\text { Umur } \\
\text { panen } \\
\text { (hst) }\end{array}$} & \multirow{2}{*}{$\begin{array}{l}\text { Jumlah } \\
\text { buah } \\
\text { dipanen }\end{array}$} & \multirow{2}{*}{$\begin{array}{l}\text { Diame- } \\
\text { ter buah }\end{array}$} & \multirow{2}{*}{$\begin{array}{c}\text { Berat } \\
\text { buah/tan } \\
\text { (g) }\end{array}$} \\
\hline & & $50 \mathrm{hst}$ & $57 \mathrm{hst}$ & & & & & \\
\hline $\mathrm{A}$ (Warani F1) & $40,8 \mathrm{c}$ & $2,7 a$ & $5,0 a$ & $100,9 a b$ & $72,6 c$ & $5,2 a$ & $3,39 \mathrm{c}$ & $170,3 a b$ \\
\hline C (G-Sakina F1) & $32,5 \mathrm{a}$ & $10,1 \mathrm{C}$ & $15,7 b$ & $93,8 \mathrm{a}$ & $64,6 a b$ & $15,9 b$ & $2,97 \mathrm{c}$ & $278,0 \mathrm{bc}$ \\
\hline E (F1 Alista) & $37,5 b c$ & $5,1 b$ & $11,5 b$ & $116,7 b c$ & $72,2 \mathrm{C}$ & $13,3 b$ & $3,54 \mathrm{c}$ & $334,9 c$ \\
\hline F (Permata F1) & $35,9 b$ & $4,8 a b$ & $11,0 b$ & $87,6 a$ & $68,9 b c$ & $11,6 b$ & $3,07 a b$ & $235,9 b c$ \\
\hline G (Victory F1) & $36,9 b c$ & $6,5 b$ & $16,1 b$ & $127,2 \mathrm{c}$ & $66,4 a$ & $16,0 \mathrm{~b}$ & 3,21abc & $316,3 c$ \\
\hline H (Sakura F1) & $36,2 b c$ & $3,8 a$ & $5,4 a$ & $101,1 a b$ & $69,2 \mathrm{c}$ & $4,9 a$ & $3,31 b c$ & $109,9 a$ \\
\hline BNT & 3,3 & 2,1 & 5,3 & 18,2 & 4,4 & 5,3 & 0,3 & 116,3 \\
\hline
\end{tabular}

Ket : Angka yang diikuti huruf yang sama pada kolom yang sama, tidak berbeda nyata menurut BNT $5 \%$

Tabel 3. Penampilan beberapa sifat tanaman pada dua kondisi lingkungan jarak tanam

(Table 3. Performance some character of six tomato variety in two space condition)

\begin{tabular}{lcccccccc}
\hline \multicolumn{1}{c}{ Lingkungan } & $\begin{array}{c}\text { Umur } \\
\text { berbunga } \\
\text { (hst) }\end{array}$ & $\begin{array}{c}\text { Jumlah } \\
\text { tandan } \\
\text { bunga } \\
50 \mathrm{hst}\end{array}$ & $\begin{array}{c}\text { Jumlah } \\
\text { tandan } \\
\text { bunga } \\
57 \mathrm{hst}\end{array}$ & $\begin{array}{c}\text { Tinggi } \\
\text { tanaman } \\
58 \mathrm{hst}\end{array}$ & $\begin{array}{c}\text { Umur } \\
\text { panen } \\
\text { (hst) }\end{array}$ & $\begin{array}{c}\text { Jumlah } \\
\text { buah } \\
\text { dipanen }\end{array}$ & $\begin{array}{c}\text { Dia- } \\
\text { meter } \\
\text { buah }\end{array}$ & $\begin{array}{c}\text { Berat } \\
\text { buah/ } \\
\text { tan }(\mathrm{g})\end{array}$ \\
\hline $\begin{array}{l}\text { Jarak tanam tunggal } \\
\text { (L1) }\end{array}$ & $38,3 \mathrm{~b}$ & 5,0 & 9,6 & $93,8 \mathrm{a}$ & $71,3 \mathrm{~b}$ & 9,7 & 3,2 & $197,8 \mathrm{a}$ \\
$\begin{array}{l}\text { Jarak tanam ganda } \\
\text { (L2) }\end{array}$ & $35,0 \mathrm{a}$ & 6,0 & 12,0 & $115,3 \mathrm{~b}$ & $66,7 \mathrm{a}$ & 12,6 & 3,3 & $283,9 \mathrm{~b}$ \\
BNT & 2,1 & tn & tn & 11,5 & 2,8 & tn & tn & 73,5 \\
\hline
\end{tabular}

Ket : Angka yang diikuti huruf yang sama pada kolom yang sama, tidak berbeda nyata menurut BNT $5 \%$

Selanjutnya jika data yang diperoleh pada

Tabel 1, dianalisis lebih lanjut dengan analisis gerombol (cluster analysis) menurut lingkungan jarak tanam, maka akan diperoleh dendogram ke enam varietas yang diuji pada lingkungan tunggal sebagaimana dapat dilihat dalam gambar 1. Dari Gambar tersebut, dapat diperoleh tiga gerombol yaitu gerombol pertama hanya varietas Warani, gerombol dua dengan varietas G-Sakina dan gerombol tiga terdiri dari empat varietas yaitu Alista, Victory, Permata dan Sakura.

Pada gambar 2 dapat dilihat dendogram ke enam varietas yang dipelajari untuk kondisi lingkungan jarak tanam ganda. Dalam gambar 2, didapat empat gerombol yaitu gerombol pertama yang tersusun dari varietas Warani dan Sakura, gerombol ke dua hanya varietas Permata, gerombol ke tiga terdiri dari varietas G-Sakina dan gerombol ke empat terdapat varietas Alista dan Victory.

Dari analisis gerombol, dapat diketahui untuk lingkungan jarak tanam tunggal diperoleh tiga gerombol dan pada jarak tanam ganda empat gerombol. Dapat diinterpretasi bahwa varietas Alista dan Victory F1 memiliki sifat-sifat yang hampir sama. Di lain pihak, untuk mendapatkan tanaman yang umur genjah dan berproduksi tinggi dicirikan dengan berat buah maka dapat dilakukan persilangan antara varietas G-Sakina F1 (tetua dengan sifat umur genjah) dan Alista F1 (tetua dengan sifat berat buah tinggi). 


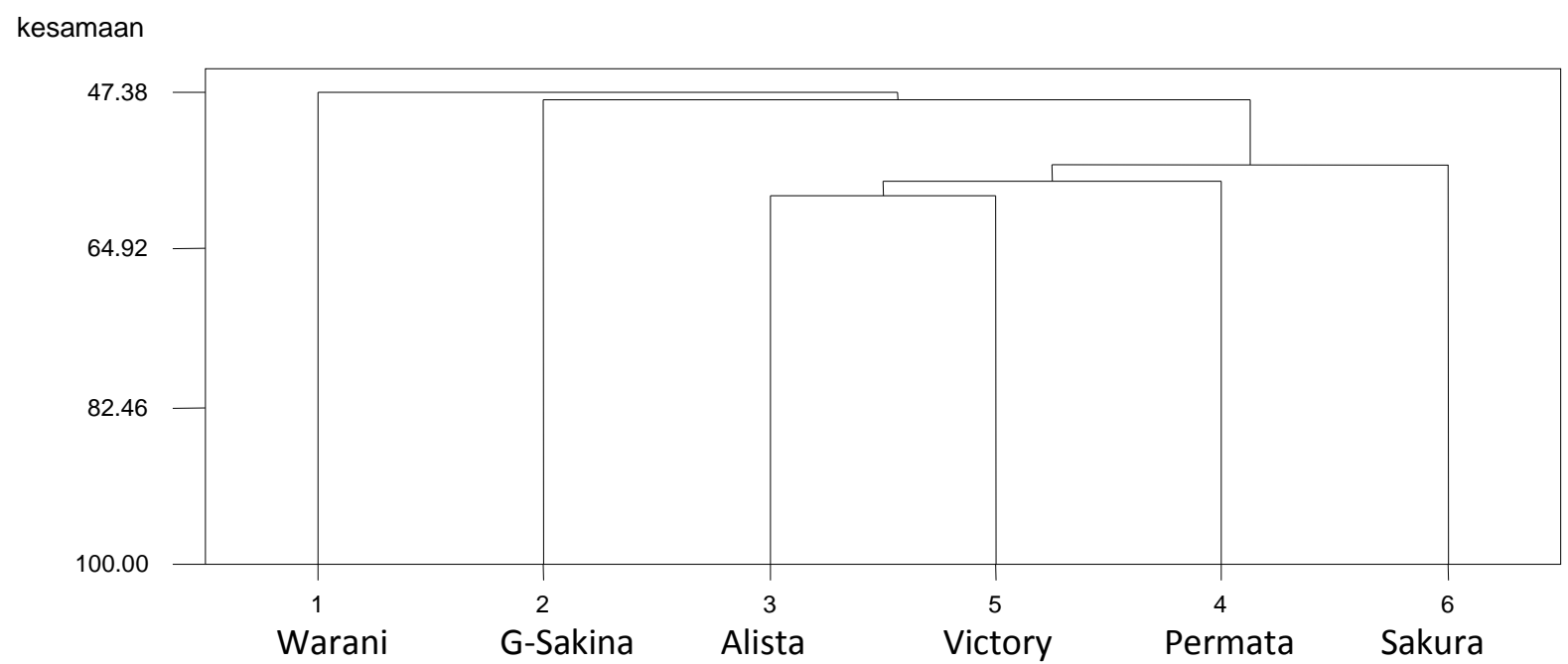

Gambar 1. Dendogram enam varietas tomat di lingkungan jarak tanam tunggal (Figure 1. Dendogram of six varieties of tamatto on single space row)

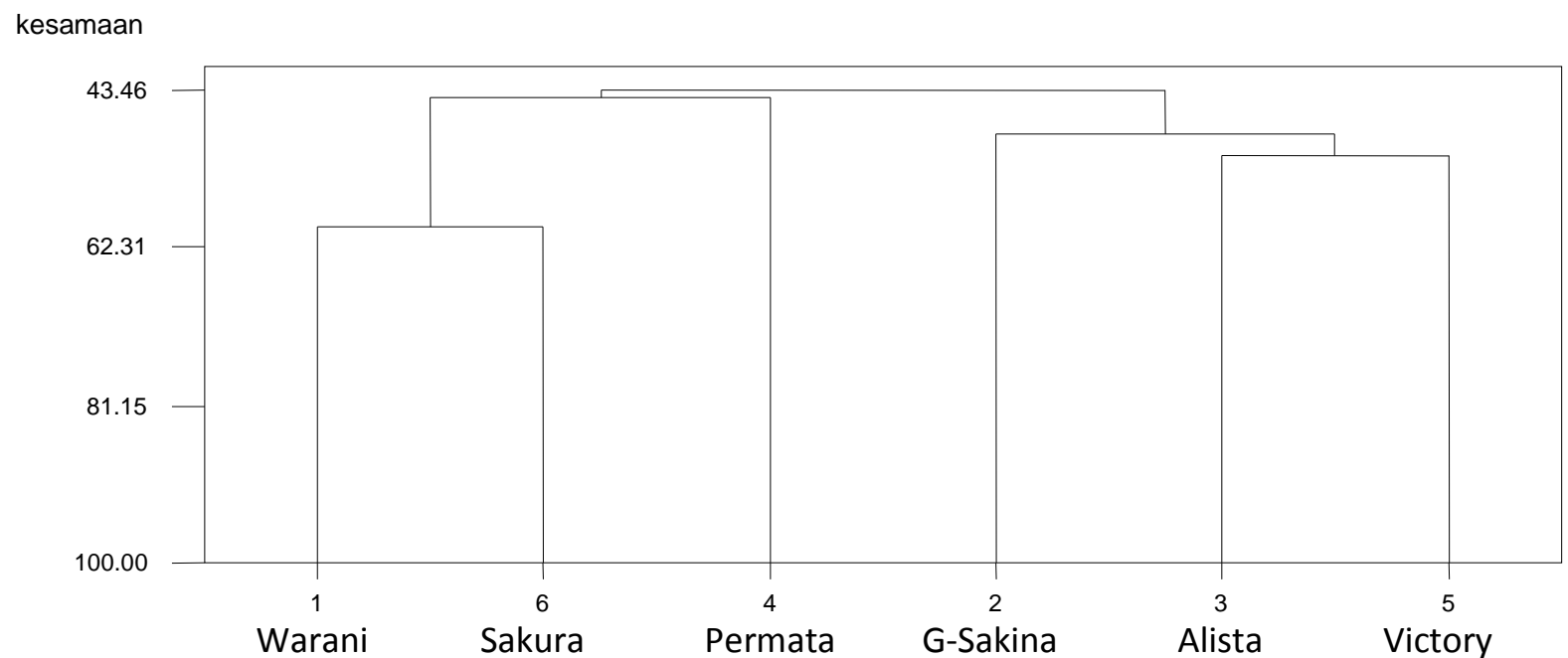

Gambar 2. Dendogram enam varietas tomat di lingkungan jarak tanam ganda (Figure 2. Dendogram of six varieties of tamatto on double space row)

\section{KESIMPULAN DAN SARAN}

\section{Kesimpulan}

Penampilan pertumbuhan dan produksi beberapa varietas tomat pada dua kondisi lingkungan jarak tanam bervariasi satu sama lain. Varietas Alista F1 (334,9 g/tan) dan Victory F1 ((316,3 g/tan) memiliki potensi berat buah dan diameter buah terbesar serta dapat digunakan sebagai materi pemuliaan. Kondisi lingkungan jarak tanam ganda memberikan respons yang lebih baik.

Pola kemiripan varietas pada ke dua kondisi lingkungan jarak tanam memberikan respons yang berbeda. 


\section{Saran}

Untuk mendapatkan hasil yang tinggi sebaiknya petani menanam varietas tomat yan direkomendasikan dengan sistem pertanaman ganda.

\section{DAFTAR PUSTAKA}

Adiyoga, W., R. Suherman, T.A. Soetiarso, B. Jaya, B.K. Udiarto, R. Rosliani dan D. Mussadad. 2004. Profil Komoditas Tomat. Pusat Penelitian dan Pengembangan Hortikultura Republik Indonesia, Jakarta.

Anonim. 2007. Pilih Varietas Sesuai Permintaan

Pasar. http:///www.agrina-online.com diakses tgl 24 Juli 2011.

Brewbaker, J.L. 1964. Agricultural Genetics. Terjemahan Santoso I. 1983. Genetika Pertanian. Seri Lembaga Genetika Modern. Gede Jaya
Dahlan, M. 1992. Peran Statistik dalam Pemuliaan Tanaman. Prosiding Simposium Pemuliaan Tanaman I. Perhimpunan Pemuliaan Tanaman Indonesia. Komisariat Daerah Jawa Timur, Surabaya Mangoendidjojo, W. 2003. Dasar-dasar Pemuliaan Tanaman. Penerbit Kanisius, Yogyakarta

Patrawisa. 2010. Budidaya Tomat. http://www. patrawisa.co/2010/10 diakses tanggal 7 Agustus 2011.

Prabowo, A.Y. 2007. Budidaya Tomat. http://teknisbudidaya blogspot.com. Diakses 13 Maret 2011. 
